\title{
Infantile-onset inflammatory bowel disease in a patient with Hermansky-Pudlak syndrome: a case report
}

Jun Ishihara', Tatsuki Mizuochi ${ }^{1 *}$, Takashi Uchida², Yugo Takaki ${ }^{1}$, Ken-ichiro Konishi ${ }^{1}$, Masahiko Joo ${ }^{3}$, Yasuhiko Takahashi ${ }^{3}$, Shinichiro Yoshioka ${ }^{4}$, Hironori Kusano ${ }^{5}$, Yoji Sasahara ${ }^{2}$ and Yushiro Yamashita ${ }^{1}$

\begin{abstract}
Background: Hermansky-Pudlak syndrome (HPS) is a rare, genetically heterogeneous disorder that manifests oculocutaneous albinism together with bleeding diatheses that reflect a platelet storage pool deficiency. Ten genetic subtypes of this autosomal recessive condition have been described to date. Some patients with Hermansky-Pudlak syndrome type 1, 4, or 6 develop Crohn's-like inflammatory bowel disease at any age including early childhood, but most often in adolescence or young adulthood. Here we report infantile-onset of inflammatory bowel disease in a patient with Hermansky-Pudlak syndrome type 1 who responded to infliximab.

Case presentation: A Japanese boy, the second child of non-consanguineous healthy parents, was born with chalky white skin, silvery-white hair, and gray eyes, representing oculocutaneous albinism. He developed frequent diarrhea and fever accompanied by weight loss at 6 months, and was diagnosed with Crohn's-like inflammatory bowel disease based on the endoscopic finding of longitudinal ulcerations in the colon and the histopathologic finding of nonspecific chronic inflammation without granulomas at the age of 11 months. Treatment with an elemental diet, salazosulfapyridine, and corticosteroids failed to improve clinical or laboratory abnormalities, and the diarrhea became bloody. At 13 months he began treatment with infliximab, which produced marked improvement followed by clinical remission. Endoscopy at 20 months demonstrated healing of the colonic mucosa. At 22 months he is in sustained clinical remission receiving only infliximab. Because albinism with inflammatory bowel disease suggested Hermansky-Pudlak syndrome, we performed genetic screening using next-generation sequencing in a targeted gene panel analysis for primary immunodeficiency disease and/or inflammatory bowel disease. The patient proved to have a compound heterozygous mutation of the HPS1 gene resulting in Hermansky-Pudlak syndrome type 1.
\end{abstract}

Conclusions: We consider this report to be the first account of type 1 Hermansky-Pudlak syndrome with infantile-onset of inflammatory bowel disease. Early administration of infliximab was effective. We recommend next-generation sequencing for patients with very early-onset inflammatory bowel disease suspected to be monogenic.

Keywords: Hermansky-Pudlak syndrome, Early-onset inflammatory bowel disease, Monogenic inflammatory bowel disease, Infliximab

\footnotetext{
* Correspondence: mizuochi_tatsuki@kurume-u.ac.jp

${ }^{1}$ Department of Pediatrics and Child Health, Kurume University School of

Medicine, 67 Asahi-machi, Kurume 830-0011, Japan

Full list of author information is available at the end of the article
}

(c) The Author(s). 2019 Open Access This article is distributed under the terms of the Creative Commons Attribution 4.0 International License (http://creativecommons.org/licenses/by/4.0/), which permits unrestricted use, distribution, and reproduction in any medium, provided you give appropriate credit to the original author(s) and the source, provide a link to the Creative Commons license, and indicate if changes were made. The Creative Commons Public Domain Dedication waiver (http://creativecommons.org/publicdomain/zero/1.0/) applies to the data made available in this article, unless otherwise stated. 


\section{Background}

Hermansky-Pudlak syndrome (HPS) is a rare, genetically heterogeneous disorder that manifests oculocutaneous albinism together with bleeding diatheses that reflect a platelet storage pool deficiency. Electron microscopically, lysosomes and related organelles in reticuloendothelial and other organs have shown lipofuscin accumulation $[1,2]$. Ten genetic subtypes of this autosomal recessive condition have been described to date $[1,3]$. Some patients with HPS, specifically those with genotype HPS-1, HPS-2, or HPS-4, are predisposed to interstitial lung disease that usually presents in mid-adulthood but rarely in late adolescence [1]. In addition, some patients with HPS, specifically HPS-1, -4 , and -6, develop Crohn's-like inflammatory bowel disease (IBD). HPS with IBD can present at any age including early childhood, but most often emerges in adolescence and young adulthood [1, 2].

We report an infantile-onset IBD patient with HPS-1 who responded to infliximab (IFX).

\section{Case presentation}

A Japanese boy was born by spontaneous vaginal delivery at 39 weeks of gestation, with a birth weight of $2616 \mathrm{~g}$. He was the second child of non-consanguineous healthy parents.
He was born with chalky white skin, silvery-white hair, and gray eyes, indicating oculocutaneous albinism. He also showed horizontal nystagmus. At 6 months of age, he developed frequent diarrhea and fever accompanied by weight loss.

At 11 months of age, he was hospitalized at Kyushu Hospital. Laboratory results included a white blood cell count of $20.3 \times 10^{9} / \mathrm{L}$ (normal range, 4.4-19.1); red blood cell count, $534 \times 10^{10} / \mathrm{L} \quad(380-523) ;$ hemoglobin, $92 \mathrm{~g} / \mathrm{L} \quad(100-142)$; platelet count, $83.6 \times 10^{10} / \mathrm{L}(22.0-76.0)$; serum total protein, $66 \mathrm{~g} / \mathrm{L}$ (53-72); and albumin, $31 \mathrm{~g} / \mathrm{L}$ (32-48). C-reactive protein was $104.5 \mathrm{mg} / \mathrm{L}(<1.4)$ and erythrocyte sedimentation rate, $71 \mathrm{~mm} / \mathrm{hr}$. $(<10)$. Prothrombin time was $14.6 \mathrm{~s}(11.0$ $15.0)$; activated partial thromboplastin time, $31.4 \mathrm{~s}$ (24.0$39.0)$; and bleeding time, $2.3 \mathrm{~min}(2.0-5.0)$. Abdominal ultrasonography and computed tomography showed bowel wall thickening in the transverse and descending colon. Endoscopy showed erosive changes, multiple aphthous ulcers, and longitudinal ulcerations in the colon, but normal mucosa in the terminal ileum (Fig. 1a and b); endoscopic biopsy specimens from the colon showed nonspecific chronic inflammation without granulomas (Fig. 1c).

Based on clinical, laboratory, and endoscopic findings, the patient was diagnosed with Crohn's-like IBD. He was

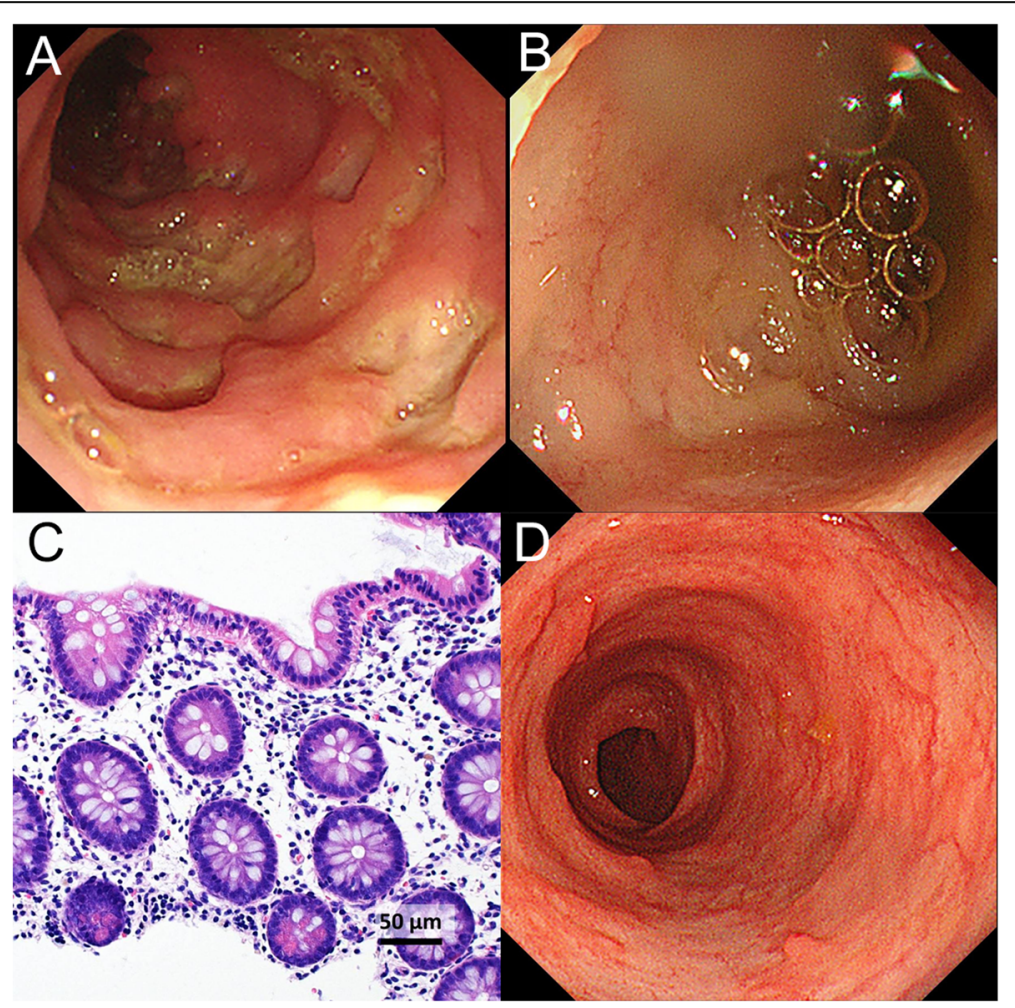

Fig. 1 Endoscopic and histopathologic findings before and after infliximab. Endoscopy before infliximab treatment showed erosive changes, multiple aphthous ulcers, and longitudinal ulcerations in the colon (a) but normal mucosa in the terminal ileum (b). Endoscopic biopsy specimens from the colon showed mild lymphoplasmacytic infiltration in the lamina propria, and Paneth cell metaplasia (c; hematoxylin and eosin stain). Endoscopy 7 months after initiation of infliximab treatment showed mucosal healing in the colon (d) 
treated with an elemental diet, salazosulfapyridine, and corticosteroids, which failed to improve clinical or laboratory findings, and bloody diarrhea ensued. Given lack of improvement, he was transferred at 13 months of age to Kurume University Hospital, where he began treatment with IFX. He soon showed marked improvement, followed by clinical remission. At 20 months of age, endoscopy showed healing of the colonic mucosa (Fig. 1d). Currently, at 22 months of age, the patient is in sustained clinical remission, receiving only IFX $(7 \mathrm{mg} / \mathrm{kg})$ every 8 weeks.

Because of albinism, nystagmus, and IBD, an association suggestive of HPS, platelet morphology was evaluated. Electron microscopy showed absence of dense bodies in platelets, which was consistent with a diagnosis of HPS. Following parental informed consent, we performed genetic screening using next-generation sequencing in a targeted gene panel analysis for primary immunodeficiency disease and/or IBD including HPS1, HPS4, and HPS6 genes (Additional file 1) [1, 4]. We identified 2 heterozygous mutations in the HPS1 gene in the patient (c.398 +5G > A and c.1323dupA) and a heterozygous mutation in each parent (father, c. $398+5 \mathrm{G}>$ A; mother, 1323dupA). These mutations have been reported previously in Japanese patients with HPS-1 [5]. We diagnosed the patient with HPS-1 resulting from compound heterozygous mutation of the HPS1 gene.

\section{Discussion and conclusions}

HPS can be caused by 10 different genotypes involving various chromosomes. These aberrant genes cause abnormal vesicle formation involving melanosomes, platelet dense bodies, and a subset of lysosomes. This results in visual impairment, skin hypopigmentation, and increased risk of bleeding $[1,3]$. IBD has been reported in patients with HPS-1, -4 , and -6 ; the pathogenetic mechanisms are unknown $[1,2]$.

IBD in HPS shows many of the same pathologic features as the more common Crohn's colitis: irregular distribution of large bowel lesions, interspersed with regions of normal mucosal architecture; superficial crypt abscesses; and prominent inflammatory cell infiltrates in involved areas [2, 6, 7]. In a study of 122 subjects with HPS, $8 \%$ overall were found to have IBD; among those with gastrointestinal symptoms, 33\% were diagnosed with IBD [2]. IBD in HPS can present at any age including early childhood but most commonly becomes evident in adolescence and young adulthood. To our knowledge, the youngest HPS patient reported to develop IBD was 2 years old [2], making our patient the youngest to present with IBD and the first reported HPS patient with IBD onset during infancy.

In some patients with HPS, conventional therapy of IBD including aminosalicylates and corticosteroids has been unsuccessful. Recent reports maintain that immunosuppressants and anti-tumor necrosis factor $\alpha$ therapy such as IFX may be effective for IBD in patients with HPS [2, 6, 7]. Use of compounds containing 5-aminosalicylic acid is an area of controversy because of the HPS platelet storage pool defect [1]. In fact, our patient is now in sustained clinical remission with colonic mucosal healing using only IFX.

Patients with a diverse spectrum of rare genetic disorders can present with IBD, a situation referred to as monogenic IBD $[4,8,9]$. Patients with these disorders often develop symptoms during infancy or early childhood, along with endoscopic or histologic features of Crohn's disease, ulcerative colitis, or unclassified IBD. HPS is considered one of the monogenic IBDs $[1,2,8]$. Distinguishing monogenic forms among IBD patients under 6 years old can be crucial in determining the best treatment. Genetic screening using next-generation sequencing is a highly useful approach to diagnosis of patients with monogenic IBD $[4,8,9]$. In this patient, the clinical features of oculocutaneous albinism with nystagmus are consistent with an underlying diagnosis of HPS [1]. Such characteristic features may aid in diagnosing specific etiologies of infantile-onset IBD. Our patient represents a case in point; we diagnosed him with HPS-1 by genetic analysis as an infant and could treat him successfully with early introduction of IFX.

In conclusion, we consider our patient to be the first known HPS-1 patient with infantile-onset of IBD. Early introduction of IFX was effective therapy. Physicians should consider genetic screening using next-generation sequencing when they treat patients with very early-onset IBD suspected to be monogenic.

\section{Additional file}

Additional file 1: List of genes responsible for pediatric IBD analyzed in this study (adapted from Reference 4). (DOCX 29 kb)

Abbreviations

HPS: Hermansky-Pudlak syndrome; IBD: Inflammatory bowel disease; IFX: Infliximab

\section{Acknowledgments \\ The authors thank the patient and his parents for their cooperation. This work is supported by grants from Japanese Ministry of Health, Labour and} Welfare (H29-013, H29-020) to YS.

\section{Funding}

This work is supported by grants from Japanese Ministry of Health, Labour and Welfare (H29-013, H29-020) to YS.

\section{Authors' contributions}

TM contributed to the concept and design of the study. JI, TM, YT1, KK, MJ, YT2, SY, HK, and YY carried out analysis and interpretation of data. TU and YS performed genetic analysis. $J$ and TM wrote the manuscript, which was edited by TU and YS. YY supervised the study and reviewed the manuscript. Thus, all authors contributed to the manuscript. All authors read and approved the final manuscript. 


\section{Ethics approval and consent to participate}

The genetic analysis protocol was approved by the Institutional Review Board at the Ethical Committee of Tohoku University. Written informed consent was obtained from the patient's parents for participating the study.

\section{Consent for publication}

Written informed consent was obtained from the patient's parents for publication of this case report and any accompanying images. A copy of the written consent is available for review by the Editor of this journal.

\section{Competing interests}

Tatsuki Mizuochi is an Editorial Board Member for BMC Gastroenterology.

Other authors declare that they have no competing interests.

\section{Publisher's Note}

Springer Nature remains neutral with regard to jurisdictional claims in published maps and institutional affiliations.

\section{Author details}

'Department of Pediatrics and Child Health, Kurume University School of Medicine, 67 Asahi-machi, Kurume 830-0011, Japan. ${ }^{2}$ Department of Pediatrics, Tohoku University Graduate School of Medicine, Sendai, Japan. ${ }^{3}$ Department of Pediatrics, Japan Community Healthcare Organization, Kyushu Hospital, Kitakyushu, Japan. ${ }^{4}$ Division of Gastroenterology, Department of Medicine, Kurume University School of Medicine, Kurume, Japan. ${ }^{5}$ Department of Pathology, Kurume University School of Medicine, Kurume, Japan.

Received: 7 June 2018 Accepted: 4 January 2019

Published online: 11 January 2019

\section{References}

1. Seward S, Gahl W. Hermansky-Pudlak syndrome: health care throughout life. Pediatrics. 2013;132:153-60

2. Hussain N, Quezado M, Huizing M, Geho D, White JG, Gahl W, et al. Intestinal disease in Hermansky Pudlak syndrome: occurrence of colitis and relations to genotype. Clin Gastroenterol Hepatol. 2006:4:73-80.

3. Ammann S, Schulz A, Krageloh-Mann I, Dieckmann NM, Niethammer K, Fuchs $S$, et al. Mutations in AP3D1 associated with immunodeficiency and seizures define a new type of Hermansky-Pudlak syndrome. Blood. 2016;127:997-1006.

4. Suzuki T, Sasahara Y, Kikuchi A, Kakuta H, Kashiwabara T, Ishige T, et al. Targeted sequencing and immunological analysis reveal the involvement of primary immunodeficiency genes in pediatric IBD: a Japanese multicenter study. J Clin Immunol. 2017:37:67-79.

5. Ito S, Suzuki T, Inagaki K, Suzuki N, Takamori K, Yamada T, et al. High frequency of Hermansky-Pudlak syndrome type 1 (HPS1) among Japanese albinism patients and functional analysis of HPS1 mutant protein. J Invest Dermatol. 2005:125:715-20.

6. Grucela AL, Patel P, Goldstein E, Palmon R, Sachar DB, Steinhagen RM. Granulomatous enterocolitis associated with Hermansky-Pudlak syndrome. Am J Gastroenterol. 2006;101:2090-5.

7. Felipez LM, Gokhale R, Guandalini S. Hermansky-Pudlak syndrome: severe colitis and good response to infliximab. J Pediatr Gastroenterol Nutr. 2010;51:665-7.

8. Uhlig HH, Schwerd T, Koletzko S, Shah N, Kammermeier J, Elkadri A, et al. The diagnostic approach to monogenic very early onset inflammatory bowel disease. Gastroenterology. 2014;147:990-1007.

9. Thiagarajah JR, Kamin DS, Acra S, Goldsmith JD, Roland JT, Lencer WI, et al. Advances in evaluation of chronic diarrhea in infants. Gastroenterology. 2018;154:2045-59.

Ready to submit your research? Choose BMC and benefit from:
- fast, convenient online submission
- thorough peer review by experienced researchers in your field
- rapid publication on acceptance
- support for research data, including large and complex data types
- gold Open Access which fosters wider collaboration and increased citations
- maximum visibility for your research: over 100M website views per year
At BMC, research is always in progress.
Learn more biomedcentral.com/submissions

